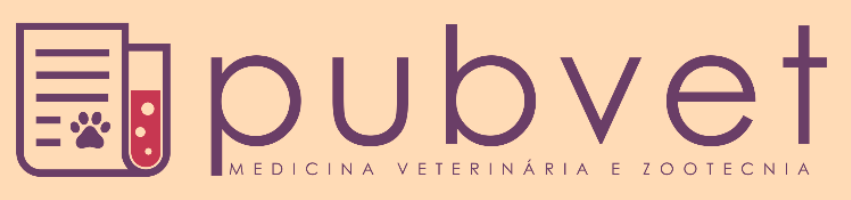

https://doi.org/10.31533/pubvet.v14n10a669.1-17

\title{
Fisioterapia e reabilitação animal na medicina veterinária
}

\author{
Tainá Bittencourt Klos ${ }^{1 *}$, Felipe Coldebella ${ }^{19}$, Fabiana Covatti Jandrey ${ }^{19}$ \\ ${ }^{I}$ Dicente da Universidade Comunitária da Região de Chapecó- UNOCHAPECÓ. Chapecó - SC Brasil. \\ *Autor para correspondência, E-mail: taina.klos@unochapeco.edu.br
}

\begin{abstract}
Resumo. A reabilitação animal na medicina veterinária é um campo recente, porém crescente a cada dia. Visa à prevenção de lesões nos diversos sistemas, aumentando a probabilidade de cura, aumento da qualidade de vida e bem-estar dos animais. A fisioterapia auxilia no tratamento de diversos problemas, estando indicada para lesões ortopédicas, oncológicas e neurológicas na clínica médica e em pacientes geriatras. $\mathrm{Na}$ reabilitação animal várias abordagens e técnicas podem ser utilizadas, como: acupuntura, fototerapia, magnetoterapia, ultrassom terapêutico, hidroesteira, laserterapia, ozonioterapia, cinesioterapia, quiropraxia e eletroterapia (FES, TENS). O objetivo da reabilitação animal é restaurar e manter funções do animal, auxiliar no alívio da dor e inflamação, melhorar qualidade de locomoção e diminuir desconfortos sentidos pelo mesmo. Sua utilização correta e feita por profissionais qualificados permitirá melhora na qualidade de vida do animal, reduzindo a gravidade de sinais clínicos e lesões. O objetivo deste artigo é conhecer a reabilitação na medicina veterinária, compreendendo suas técnicas e terapêuticas.
\end{abstract}

Palavras chave: animais, reabilitação, tratamento, veterinária

\section{Physiotherapy and animal rehabilitation in veterinary medicine}

\begin{abstract}
Animal rehabilitation in veterinary medicine is a recent yet growing every day field. It aims to prevent injuries in all various systems, increasing the probability of cure, the quality of life and welfare of the animals. Physiotherapy assists in the treatment of several problems, being indicated for orthopedic, oncological and neurological injuries, in the medical clinic and in geriatric patients. In animal rehabilitation various approaches and techniques can be used, such as: acupuncture, phototherapy, magnetotherapy, therapeutic ultrasound, hydrostatic, laser therapy, ozone therapy, kinesiotherapy, chiropractic and electrotherapy (FES, TENS). The objective of animal rehabilitation is to restore and maintain the animal's functions, assist in relieving pain and inflammation, improving quality of locomotion and reducing the discomfort felt by them. Its correct use and if done by qualified professionals will allow an improvement in the animal's quality of life, reducing the severity of clinical signs and injuries. The objective of this article is to know the possibilities of rehabilitation in veterinary medicine, understanding its techniques and therapies.
\end{abstract}

Keywords: animals, rehabilitation, treatment, veterinary

\section{Introdução}

A fisioterapia começou a ser utilizada em animais por volta dos anos 70 , os primeiros animais a serem utilizados para a aplicação das técnicas fisioterápicas foram os cavalos, depois disso as técnicas aplicadas foram aumentando e passaram por diversos aperfeiçoamentos, a fim de atender uma maior diversidade de espécies (Alves et al., 2019). 
A fisioterapia e a reabilitação animal possuem características diferentes entre si, porém as duas atuam juntas para auxiliar a completa recuperação do animal. A fisioterapia busca proporcionar a cicatrização e recuperação dos tecidos através da utilização de máquinas apropriadas ou técnicas terapêuticas, já a reabilitação animal foca na reeducação dos movimentos do animal (Ferreira, 2010).

A fisioterapia e reabilitação animal tornaram-se um campo de atuação especifico dentro da medicina veterinária há muito pouco tempo, e se transformaram em uma grande área de influência para promover o bem estar animal. Elas atuam de forma conjunta com a clínica médica buscando auxiliar no tratamento dos pacientes, proporcionando bem estar e melhor qualidade de vida, elas facilitam a redução dos sinais clínicos, promovem alivio da dor, ajudam a eliminar a causa primária da doença e ainda a restituir as funções normais do animal de forma mais rápida e eficaz (Alves et al., 2019).

A fisioterapia veterinária é considerada pelo Conselho Federal de Medicina Veterinária prática exclusiva do Médico Veterinário, protegida pela Legislação Federal, sob a Resolução ${ }^{\circ} 850$ de 05 de dezembro de 2006. Neste documento diz que, apenas este profissional é habilitado e capacitado para interpretar os sinais clínicos e laboratoriais, as alterações multifuncionais e instituir um diagnóstico, tratamento, prognóstico e medidas preventivas relativas à saúde e bem-estar animal (Kistemacher, 2017).

Os objetivos principais para utilização da fisioterapia são: eliminar a fonte da disfunção, reduzir os sinais clínicos e aliviar a dor. A dor é um dos principais fatores que afeta o bem-estar dos pacientes, podendo causar imunossupressão, inapetência, caquexia, e até induzir o paciente à redução ou desuso dos membros acometidos. A fisioterapia auxilia também na redução da inflamação, melhora a irrigação sanguínea, propicia uma melhor cicatrização, estimula o sistema nervoso, previne a neuropraxia e o entorpecimento muscular, ajuda ainda a prevenir ou diminuir a atrofia de músculos, cartilagem, ossos, tendões e ligamentos, contribui para impedir ou reduzir a formação de aderências e a retração de tecidos, favorece a redução de contraturas e tensão muscular, pode auxiliar também na redução de peso, entre outros benefícios (Ferreira, 2010).

A fisioterapia pode ser indicada, por exemplo, para reabilitação pós-cirúrgica em casos ortopédicos e neurológicos, lesões músculo-esqueléticas como tendinites, bursites e entorses, mobilidade reduzida, fraqueza muscular, doença dos discos intervertebrais associada a dor e paresia, lesões articulares como contraturas e artrites, displasia cotovelar e coxofemoral, cicatrização de feridas, alterações no desempenho no caso de um animal atleta, edemas, problemas na circulação sanguínea e linfática e complicações do sistema cardiorrespiratório (Alves et al., 2019; Ferreira, 2010).

Para todos os objetivos e indicações que a fisioterapia e reabilitação animal possuem, existem diversas técnicas que podem ser empregadas no tratamento dos pacientes, conforme a necessidade e particularidade de cada um. Para dar início ao tratamento de forma adequada a cada paciente, é preciso realizar então uma anamnese muito detalhada e fazer um exame físico bastante criterioso, sendo assim, entender a queixa principal, qual a sintomatologia que o animal apresenta e como se deu a evolução do quadro clinico é de extrema importância para se chegar a um diagnóstico e constituir um plano de tratamento. Em alguns casos, para se ter certeza do diagnóstico é preciso recorrer a exames complementares como a radiografia, ou a exames ainda mais específicos como a tomografia axial computorizada (TAC) e a ressonância magnética nuclear (RMN), isso irá permitir uma avaliação muito mais precisa do real quadro do paciente. É importante ressaltar neste ponto, que nunca se deve iniciar qualquer tratamento ao paciente sem possuir um diagnóstico clínico final (Alves et al., 2019; Ferreira, 2010). Desta forma veremos a seguir alguns dos recursos disponíveis que podem ser utilizados dentro da fisioterapia e reabilitação e animal.

\section{Hidroterapia}

Segundo a Canine Hydrotherapy Association, a associação do tratamento veterinário com a hidroterapia pode melhorar a qualidade e a taxa de recuperação de animais pós cirurgia ou lesão traumática. Também auxilia animais jovens diagnosticados com problemas de desenvolvimento, pois tem efeito terapêutico específico em tecidos corporais.

A hidroterapia permite intervenção mais rápida, sendo que os pacientes conseguem se movimentar apenas alguns dias após a cirurgia ou trauma, com pouco risco de se relesionar (Konlian, 1999). 
Existem várias formas de hidroterapia. Piscinas podem ser usadas para a prática do nado, fazendo com que o terapeuta possa alterar o modo como o animal está exercitando o membro. Hidroesteiras também são utilizadas e fornecem a oportunidade de controlar a velocidade da esteira, o nível da água, a temperatura e o aclive (Waining et al., 2011). Existem ainda exercícios terapêuticos aquáticos que envolvem andar, fazer transferências de peso e ficar apoiado em todos os membros (Bockstahler et al., 2004).

Os benefícios desse tipo de terapia incluem alívio da dor, diminuição de inchaço e rigidez, ganho de força muscular, melhora circulação sanguínea, aumento de recuperação tecidual, maior amplitude de movimento nas articulações, recuperação mais rápida, resistência cardiovascular e muscular, reestabelecimento da marcha e melhora de propriocepção (Marsolais et al., 2003; Monk et al., 2006).

Animais com doenças variadas podem se beneficiar da hidroterapia, as recomendações para esse tipo de terapia incluem diagnósticos como displasia de cotovelo e quadril, osteocondrite, luxação de patela; condições degenerativas, como a osteoartrite primária e secundária a desenvolvimento de espondilose; para casos pré e pós cirúrgicos, como excisão de cabeça e colo femoral, artroscopia, ruptura do ligamento cruzado cranial e luxação de patela; condições neurológicas, como mielopatia degenerativa, estenose espinhal, protrusão do disco intervertebral, embolismo fibro-cartilaginoso, trauma espinhal, discoespondilite, doença neuromuscular ou neuropatias periféricas; em casos de lesões de tecido mole, como tendinite, deformação de ligamento, tendinopatias e torções musculares, bem como tratamento para obesidade.

$\mathrm{Na}$ hidroterapia, são levadas em conta as propriedades físicas da água, tais como densidade, flutuabilidade, gravidade específica, viscosidade, tensão superficial, pressão hidrostática e refração (McGowan \& Goff, 2016).

Para Carrie \& Brody (2005), a flutuabilidade fornece uma força ascendente que tem relação com a profundidade e gravidade específica da água. Isso pode ser estendido à área veterinária, levando em conta que os animais que apresentam dificuldade locomotora ou a se pôr em pé contra a força gravitacional, muitas vezes são capazes de se pôr em pé na água por conta da ação da flutuabilidade, tendo menos força gravitacional exercida sob os membros.

A pressão hidrostática ajuda na redução de edema, já que tende a produzir centralização de fluídos (Gross, 2007).

O nado em piscina é frequentemente usado como parte do programa de reabilitação para o paciente canino após a cirurgia para correção de deficiências do ligamento cruzado. Um programa de exercícios de fisioterapia e exercícios de nado, iniciado três semanas após a cirurgia, demonstrou melhorar a função dos membros, sem diferença evidente entre os membros afetados e não afetados medidos com uma placa de força 6 meses após a cirurgia (Marsolais et al., 2003).

Conforme Mikail \& Pedro (2009), o nado em piscina melhora débito cardíaco e retorno venoso, aptidão respiratória, tônus muscular, aumenta a amplitude de movimento articular e evita total depósito de peso no sistema locomotor.

A terapia com hidroesteira tornou-se recentemente muito popular para a reabilitação das lesões em cães. Nessa modalidade pode-se controlar a velocidade, inclinação e volume de água a qual o animal terá contato (Carr \& Canapp, 2014; Ferreira, 2010).

A cinemática articular dos cães estudados enquanto caminhavam em uma esteira subaquática, mostrou que a flexão articular é maior quando o nível de água fica acima da articulação de interesse, mas essa extensão total da articulação também é alcançada com a caminhada na esteira subaquática, o que não é o caso na natação (Jackson et al., 2002).

A amplitude de movimento do joelho foi comparada em um grupo de cães nadando contra aqueles que se exercitam em uma esteira normal após cirurgia de estabilização do ligamento cruzado cranial. Foi alcançada uma maior flexão de joelho enquanto nadavam, em relação ao exercício na esteira, então recomenda-se a hidroterapia se o objetivo é aumentar a flexão de joelho no paciente (Marsolais et al., $\underline{2003})$. 
Andar embaixo da água pode ser útil em casos de animais com ataxia, com auxilio manual ou com pesos a nível de tarso e carpo (Bockstahler et al., 2004).

Bockstahler et al. (2004), também sugere que o exercício de transferência de peso subaquático auxilia na propriocepção, fortalecimento muscular e treino de coordenação. Para tanto, é criado um fluxo de turbulência lateral, cranial ou caudal, que obriga o animal a aumentar a força aplicada para ir contra o movimento da água.

O mesmo autor cita que o movimento de pedalar também pode ser empregado na hidroterapia, sendo útil no auxílio da formação do padrão da passada, propriocepção e pode manter ou aumentar a amplitude da articulação. Para este exercício o paciente deve estar apoiado sob os quatro membros, dentro da água, e o terapeuta faz o movimento circular de marcha com um dos membros, segurando a pata a ser trabalhada.

O fisioterapeuta veterinário precisa avaliar se o paciente pode ser indicado ao tratamento com hidroterapia. Alguns fatores incluem condição médica e física, temperamento, se o animal já era acostumado a nadar, ou se tem aversão ou experiências ruins com água (McGowan \& Goff, 2016). O mesmo autor cita que a maioria dos animais se apresenta apto a este tipo de terapia, e mesmo os que são mais desconfiados se acostumam depois de algumas visitas, então a perseverança vale a pena.

É preciso ter máximo cuidado a qualquer sinal de fadiga ou stress durante o exercício, que podem ser observados como o animal puxar o queixo para baixo, respiração evidentemente forçada, procurar as bordas da piscina, diminuição do ritmo da marcha na hidroesteira, e em cães, o aplainamento das orelhas (Levine et al., 2008).

Assim como todo o tipo de terapia, a hidroterapia deve ser avaliada em duração, intensidade e frequência do tratamento, sendo que o animal deve ser monitorado a acompanhado em cada uma das sessões, levando em conta a progressão positiva ou não do tratamento e os tipos de abordagem (McGowan \& Goff, 2016).

A hidroterapia não é recomendada a pacientes com as seguintes condições: feridas abertas, infeccionadas ou supurando, animais que tem incisões cirúrgicas sem uma cobertura a prova da água, debilidade extrema, afecções gastrointestinais presentes (diarreia ou vômito), febre ou infecção, epilepsia não compensada, comprometimento ou angústia respiratória, doenças infecto-contagiosas e comprometimentos sistêmicos (cardiopatias, hepatopatias ou doença renal severas, hipertensão ou hipotensão).

Alguns animais que apresentam doenças de pele, de ouvido, incontinência urinária ou fecal, idosos ou em obesidade extrema podem ser candidatos à tratamento com hidroterapia dependendo do equipamento e instalações do local, bem como ter permissão e acompanhamento do veterinário.

\section{Laserterapia}

Também conhecida como fotobiomodulação, fotobioestimulação, laser terapêutico, laser frio ou ainda terapia por laser de baixa potência. O laser é um acrônimo para "light amplification by stimulated emission of radiation" (amplificação da luz por emissão estimulada de radiação) é um tratamento não invasivo e não farmacológico que usa radiação eletromagnética para emitir uma luz que causa reações fotóticas e químicas sem produzir calor (Mikail \& Pedro, 2009).

A laserterapia é comumente utilizada no tratamento de distúrbios ortopédicos, neurológicos e musculo-esqueléticos, sendo as afecções mais comuns indicadas a este tratamento as lesões de tecidos moles, feridas, doença do disco intervertebral, osteoartrite, problemas dermatológicos e dor aguda, crônica e pós cirúrgica (Riegel \& Godbold, 2017).

McGowan \& Goff (2016), detalha os tipos de condições que podem ser tratadas com laserterapia: tendinite, miosite, sinovite, bursite, artrite reumatoide, oesteoartrite, calcificações, doenças autoimunes, lesões por esforço repetitivo, fraturas, subluxações, rupturas musculares, traumas em tendão, feridas por compressão, abrasões cutâneas, ulcerações diabéticas, etc. 
Em feridas cutâneas, segundo Andrade et al. (2014), a laserterapia promove neoangiogênese, revascularização, síntese de colágeno, efeitos anti-inflamatórios, proliferação de fibroblastos e tecido epitelial e contração da lesão.

O funcionamento dessa terapia se dá pela absorção da luz no tecido por moléculas chamadas cromóforos, que são encontrados nas mitocôndrias. Baseada nessa absorção, a energia da luz é transformada em energia bioquímica, que causa uma variedade de reações secundárias, resultando em modulação das funções celulares e estimulação dos mecanismos de reparação tecidual (McGowan \& Goff, 2016). Ainda segundo o mesmo autor, condições como alteração da condução nervosa, mudanças na circulação sanguínea, aumento do metabolismo de opiáceos, acetilcolina e serotonina, estimulação da angiogenese, aumento da produção de ATP celular podem ser alcançadas com a irradiação de laser, tendo como efeito a modulação de eventos secundários, como liberação de fatores de crescimento, replicação celular e aceleração da cicatrização vagarosa de tecidos lesados.

Existe uma variedade de lasers que são utilizados na laserterapia veterinária, como Argon, $\mathrm{CO}^{2}$, GaAIAs (Gallium-Aluminum-Arsenide), $\mathrm{HeCd}$, HeNe e Krypton, sendo que o HeNe é considerado o melhor laser para bioestimulação (Al-Watban \& Andres, 2000).

A efetividade dessa terapia é dependente de fatores como comprimento de onda, dose, potência e tempo empregados no tratamento (Al-Watban \& Andres, 2000; Channual et al., 2008).

Em estudos realizados por Demir et al. (2004), a laserterapia mostrou aceleração das reações bioquímicas, fibroblásticas, aumentou a neovascularização e o metabolismo de colágeno, demonstrou efeito antibacteriano e benéfico nas fases proliferativas e inflamatórias de lesões.

As contraindicações desse tratamento são principalmente relacionadas a pacientes com suspeita de carcinoma ou que tenham comprovadamente a afecção, em áreas hemorrágicas e em fêmeas prenhas (McGowan \& Goff, 2016).

Frigo et al. (2009) demonstram que houve piora da doença em casos onde células malignas de melanoma foram tratadas por laserterapia usando Índio-Gálio-Alumínio-Arsênio-Fósforo.

A utilização dessa terapia também é contraindicada em casos de tumor maligno, na tireoide, em hipersensibilidade, epilepsia e em trombose em veias pélvicas ou profundas dos membros inferiores (Bjordal et al., 2008; Moshkovska, 2005).

\section{Ozonioterapia}

A ozonioterapia é um método terapêutico que utiliza o gás ozônio $\left(\mathrm{O}_{3}\right)$ principalmente por suas propriedades bactericidas, fungicidas e viricidas (Lake et al., 2004).

O ozônio, por ser um gás instável, acaba se degradando com facilidade e volta a seu estado estável, tendo como resultado a formação de $\mathrm{O}_{2}$, átomos livres de oxigênio e radicais livres, que por sua vez são extremamente reativos e oxidam compostos orgânicos, inorgânicos, bactérias e vírus a que vierem a ter contato (Lam, 2008).

Em relação a ação bactericida, acredita-se que o ozônio ataque a parede celular da bactéria, e em seu interior promova a oxidação dos ácidos nucleicos e aminoácidos (Gurley, 1985).

O ozônio tem a capacidade de melhorar a oxigenação e o metabolismo corporal por consequência, após ser introduzido no organismo (Pino et al., 1999). Possui também a capacidade de ativar linfócitos T, estimular a produção de citocinas, fazer síntese de anticorpos, oxidação de compostos orgânicos e inorgânicos, aumento da oxigenação e do metabolismo celular através de vasodilatação e aumento da resposta enzimática oxidativa (Lake et al., 2004; Velano et al., 2001). A terapia com ozônio também reduz a agregação plaquetária, age como antiinflamatório e antialérgico (Haddad et al., 2009).

O ozônio garante melhor suprimento de oxigenação nos tecidos pois aumenta a flexibilidade das hemácias, facilitando sua passagem pelos capilares sanguíneos (Leite, 1999). Também é estimulante do sistema retículo-endotelial e atua como analgésico (Hernández \& González, 2001).

Outra ação descrita é a de imunomodulador, conforme a dose, melhorando anemias e circulação sanguínea ( $\underline{\text { Rifá \& Musa, 2005) }}$. 
Já existem estudos científicos que demonstram a efetividade do uso da ozonioterapia veterinária como associação ao tratamento medicamentoso em casos de lesões cutâneas causadas por fungos, em casos de leishmaniose (Gonçalves et al., 2020), dermatites bacterianas (Borges et al., 2019), na diminuição dos níveis séricos de ureia e creatinina em cães com leishmaniose (Moda et al., 2014), tratamento de lesões cutâneas e eritrema em cães infestados por carrapatos através do uso de óleo ozonizado (Oliveira et al., 2014), além de auxiliar no tratamento de displasia coxofemoral, estreitamento de espaço de disco intervertebral, calcificação de disco intervertebral (T12-T13), estreitamento leve de espaço de disco intervertebral (C5-C6, C6-C7, L4-L5) e até lipidose hepática felina (Di Maio et al., 2009). Há também estudos que apontam a diminuição de aplicações de sulfato de vincristina no tratamento de tumor venéreo transmissível (Souza, 2009).

Na medicina humana, assim como na veterinária, há certo ceticismo em relação aos efeitos clínicos e biológicos dessa terapia, surgindo da conscientização da toxicidade do ozônio e da diminuta comprovação científica (Viebahn, 1994).

Nogales et al. (2008) afirma que a solução de ozônio a ser utilizada na terapia deve ser preparada logo antes do uso, pois a molécula de $\mathrm{O}_{3}$ é instável e pode retornar a forma de oxigênio $\left(\mathrm{O}_{2}\right)$.

Para Viebahn-Haensler (2001), a ozonioterapia não deve ser a única e principal terapia empregada no tratamento de doenças, mas sim estar associada com outros procedimentos terapêuticos.

Os modos de administração da ozonioterapia podem variar, sendo alternativas viáveis a injeção subcutânea, intrarticular, intramuscular, intradiscal, intravaginal, insuflação retal e uretral, autohemoterapia maior ou menor, óleo ozonizado, água ozonizada (Bocci, 2005; Bocci et al., 2011) e a técnica "bag" (

Os tratamentos tópicos, como as técnicas que utilizam "bag", touca ou bolsa são eficazes como recurso terapêutico de lesões como feridas abertas, escaras, úlceras e pós-operatórias. Utiliza-se um sistema fechado que reveste o membro acometido, liberando o gás por até 30 minutos (Oliveira, 2007).

A injeção intrarticular é feita através da aplicação do gás no interior de uma articulação. É recomendada em casos de artrite séptica (Vilarindo et al., 2013).

A insuflação retal é bastante usada em animais domésticos, pois permite mais facilidade de administração e não exige contenções físicas trabalhosas. A ozonioterapia é absorvida pela mucosa intestinal, sendo uma boa opção para os pacientes que não podem receber o gás por via intravenosa (Oliveira, 2007).

A autohemoterapia maior consiste em coletar sangue através de venopunção, misturar com ozônio e administrar novamente por via intravenosa. A autohemoterapia menor é feita da mesma maneira, porém infundida por via intramuscular, e não intravenosa (Garcia et al., 2008). A grande reatividade do ozônio faz com que as reações bioquímicas do sangue ocorram em poucos segundos.

Essa terapia vem sendo utilizada e estudada na medicina veterinária por conta de seu baixo custo e fácil aplicabilidade quando comparada com outras técnicas e intervenções farmacológicas (Silva et al., 2014). Deve-se ter cuidado na utilização e realização desta terapia pois o gás ozônio pode ser tóxico quando inalado diretamente, causando irritação das vias aéreas superiores, rinite, náuseas e êmese (Nakao et al., 2009).

\section{Magnetoterapia}

A magnetoterapia consiste na aplicação terapêutica de campos magnéticos produzidos por corrente elétrica, onde desenvolvem uma função terapêutica nos tecidos sujeitos a essa influência (Agne, 2016). Existem dois tipos de terapia por meio de campos magnéticos (magnetoterapia), a que utiliza campo magnético estático e a de campo magnético pulsátil (Levine et al., 2008).

Campo magnético estático: os magnetos estáticos estão presentes ao redor de substâncias magnetizadas (ferro, alumínio), e não sofrem variações de intensidade. Estes magnetos podem ser acoplados em diversos acessórios como colchões, capas, botões para o tratamento de áreas pontuais. Esta terapia gera um campo magnético contínuo, ocasionando um efeito térmico que desencadeia alterações fisiológicas (relaxamento). Sua terapêutica inclui o aumento no fluxo sanguíneo local, 
liberação de endorfinas e efeitos anti-inflamatórios (Levine et al., 2008). Campo magnético pulsátil: A terapia magnética pulsátil gera energia através de uma corrente elétrica que passa por um condutor em espiral, criando um campo magnético ao redor. Esta terapia gera menos efeito térmico, porém uma ação estimulante ou de ativação celular mais eficiente. Está indicada para reparações ósseas, favorecendo a reparação, pois promove a estimulação do cálcio (Mikail \& Pedro, 2009).

O mecanismo de ação do campo magnético não é totalmente conhecido, acredita-se que a matriz celular e a reparação de tecidos estão reguladas por agentes químicos (citocinas, fatores de crescimento) e físicos (estímulo mecânico e elétrico) (Mikail \& Pedro, 2009). Segundo Sterin (2001), a consolidação óssea ocorre pela ativação do metabolismo do cálcio promovido pelo campo magnético.

De acordo com Levine et al. (2008) para oferecer melhores resultados terapêuticos, os magnetos devem ser aplicados diretamente sobre a área tratada, pois ocorre redução significativa do campo magnético com pequenos distanciamentos. A magnetoterapia é indicada para: reparação de fraturas, prevenção de perda de massa óssea, osteoartrites, osteoporose, tendinites, periostites, feridas crônicas e necrose asséptica da cabeça do fêmur (Mikail \& Pedro, 2009). Esta terapia deve ser utilizada como complemento a outros tratamentos (Levine et al., 2008). Vários trabalhos mostram a eficiência em relação ao campo magnético pulsátil, já para a utilização do campo magnético estáticos faltam estudos que comprovem sua eficácia (Mikail \& Pedro, 2009).

\section{Ultrassom terapêutico}

O ultrassom terapêutico é uma forma de energia (ondas acústicas), imperceptíveis ao ouvido humano (ultrassonoras), acima de $20.000 \mathrm{~Hz}$ (Levine et al., 2008). Estas ondas são produzidas por vibrações de um cristal localizado dentro de um transdutor, deve-se movimentar este dispositivo de maneira uniforme evitando lesões por aquecimento e padronizando os efeitos desejados da terapia (Plaja, 2003). O contato do transdutor só ocorre por meio de liquido ou sólido, pois é incapaz de atravessar o ar, devendo-se fazer o uso de géis específicos para o procedimento (Mikail \& Pedro, 2009).

Aparelhos utilizados para fisioterapia produzem de um a três $\mathrm{MHz}$, atingindo cerca de sete e três centímetros de penetração (Plaja, 2003). Segundo Mikail \& Pedro (2009) os transdutores com frequências mais altas ( $3 \mathrm{MHz}$ ) são recomendados para tecidos superficiais, pois sua energia é absorvida mais rapidamente. Já em tecidos mais profundos utilizam-se frequências menores (1 MHz), possibilitando uma penetração mais profunda. Em tecidos com maior quantidade proteica (ligamentos, tendões, fáscias, cápsula articular e tecido cicatricial) as ondas sonoras serão mais bem absorvidas. É importante conhecer sempre a capacidade de absorção de cada tecido, para que o efeito terapêutico seja gerado adequadamente (Agne, 2016).

Os efeitos terapêuticos do ultrassom são divididos em efeitos térmicos e efeitos não térmicos. Efeitos térmicos: aumento do fluxo sanguíneo, da atividade enzimática, condução do estimulo nervoso, limiar de dor e reduz espasmos na musculatura. A temperatura deve aumentar de 1 a $4^{\circ} \mathrm{C}$ (Levine et al., 2008). Efeitos não térmicos: resulta da vibração das ondas acústicas, que provocam compressão e rarefação. Pode ocasionar o aumento da deposição de colágeno, proliferação de fibroblastos, angiogênese, alterações na permeabilidade da membrana aos íons de cálcio e liberação de histamina (Levine et al., 2008). O modo contínuo do ultrassom ocasiona um efeito térmico, indicado no tratamento de processos crônicos ou pós-operatório tardio (Martín, 2014). O modo pulsado permite momentos de resfriamento (efeitos não térmicos), limitando o efeito térmico e minimizando-o, sendo indicado para o tratamento de processos agudos, subagudos ou pós-operatórios (imediato ou recente) (Agne, 2016).

O ultrassom pode ser utilizado no tratamento de: tendinite, contratura articular, cicatrização de feridas, consolidação óssea, dor, espasmos musculares e dor crônica. Esta terapia deve ser evitada nos olhos, gânglios cervicais, ouvido, coração, animais gestantes, feridas contaminadas e neoplasias (Levine et al., 2008).

\section{Fototerapia}

Fototerapia é definida como a emissão de laser e diodos superluminosos de baixa potência (500 MW ou menos), (Baxter \& McDonough, 2007). Segundo Mattos (2012) esta terapia baseia-se no uso de 
baixos níveis de energia da luz, promovendo efeitos atérmicos e não traumáticos aos tecidos, muito utilizado na redução de inflamações e reparação de diversos tecidos corporais.

Os Lasers e os LEDS são semelhantes diferenciando-se apenas na forma de geração das ondas, estas fontes são utilizadas na fototerapia e seus mecanismos são semelhantes em relação à luz que é gerada, pois produzem uma banda espectral estreita, sendo o espectro do LED mais largo. O LED não percorre uma direção exata perdendo potência na penetração de tecidos, diferente do laser que possui feixes paralelos. Atualmente sabe-se que LEDs alcançam também resultados satisfatórios, semelhantes ao dos lasers (Pinheiro et al., 2017).

O Laser é classificado pela sua potência, intensidade e tempo de reflexão. Podem ser divididos em seis classes: Classe 1, lasers que possuem menor intensidade (utilizados em códigos de barras); Classe 2 e 3B, utilizados na terapêutica veterinária (potência entre 1-500 MW); Classe 4 e 5, estão presentes os laser de alta potência (maior que $500 \mathrm{MW}$ ), representam riscos aos olhos e pele (obertson et al., 2009).

A fototerapia é capaz de induzir processos fotobiológicos nas células por estimulação dos fotorreceptores, porém permanece desconhecido seu mecanismo de ação. A interação do laser é o mesmo que o utilizado em outras radiações eletromagnéticas, diferenciando-se apenas nas características de cada tecido, comprimento da onda e ângulo (Kitchen \& Partridge, 1991). A fonte deve estar em contato direto com o tecido para a maior taxa de absorção de luz e um ângulo de 90 graus, evitando a dispersão (Low et al., 2001).

O tratamento com fototerapia pode ser classificado como de curto e longo prazo. Os efeitos de curto prazo levam a produção de cortisol, auxiliando o organismo no estresse associado a doença em si (Liu et al., 2009). Segundo Venezian et al. (2010) os tratamentos de longo prazo possuem um maior efeito, devido ao seu efeito ser cumulativo. Seus efeitos terapêuticos auxiliam também na reparação tecidual e possuem um efeito anti-inflamatório (Chen et al., 2011).

\section{Acupuntura}

A acupuntura é conhecida como a inserção de agulhas ou transferência de calor em pontos definidos (acupontos) e surgiu há vários anos através da Medicina Tradicional Chinesa (MTC). Age regulando estados funcionais do organismo atingindo também a homeostase (Draehmpaehl \& Zohmann, 1997). Segundo Scognamillo-Szabó \& Bechara (2001) o estímulo de uma região age sobre as outras, ocorre a terapia reflexa. $\mathrm{Na}$ acupuntura ocorre uma estimulação sensorial ou neural periférica, ocasionando a liberação de neuropeptídios locais e a distância pelo sistema nervoso central periférico (Dawidson et al., 1999).

Os acupontos utilizados na acupuntura são descritos como canais que conduzem a energia pelo organismo (Cassu, 2002). O acuponto é uma área cutânea que possui baixa resistência elétrica e grandes concentrações nervosas, plexos nervosos, capilares e vênulas, localizadas entre músculos ou entre músculo e um tendão ou osso. A manipulação da agulha ocasiona uma lesão no tecido conjuntivo, estimulando vários sensores e gerando também alterações no fluxo do sangue ou citocinas, resultando na modulação geral da informação sensorial por um longo período, fazendo o efeito da acupuntura durar horas ou até dias (Langevin et al., 2001). Segundo Yamamura (2002), os resultados obtidos através da acupuntura estão diretamente ligados aos estímulos feitos nos acupontos (intensidade, frequência e duração do estímulo).

Para a acupuntura utilizam-se agulhas descartáveis feitas com aço-inoxidável, de diversos calibres e comprimentos (de acordo com o porte do animal). Deve-se avaliar também a profundidade, ângulo, inserção, manipulação e remoção das agulhas (Altman, 1997). Antes de qualquer procedimento no animal, uma avaliação física completa deve ser feita, incluindo anamnese e possível diagnóstico (Haltrecht, 1999). O animal deve ser posicionado em decúbito lateral ou em estação e contido, fazendo a inserção das agulhas durante 20 a 30 minutos (Altman, 1992). Em casos agudos, a acupuntura pode ser utilizada a cada dois a três dias e, em casos crônicos utilizar uma vez por semana, por um período de sete semanas. Quando estabilizar a situação, diminuir a frequência para intervalos de quinze dias. Após este período deve-se avaliar o animal a cada três a seis meses, dependendo do problema apresentado (Haltrecht, 1999). 
A indicação da acupuntura pode ser feita em diversos casos, como: recuperação motora, analgesia, regulação da imunidade, regulação de funções orgânicas do corpo, melhora de funções mentais e endócrinas e ativação de processos regenerativos (Noris, 2003). Indicada também para desordens neurológicas e musculoesqueléticas (paralisias e paresias por patologias de disco intervertebral, espondilites), desordens reprodutivas, desordens urinárias (nefrites, cistites, uretrites, urolitíases, alterações na micção), desordens gastrintestinais, sequelas de infecções virais (cinomose) e doenças auto-imunes. Problemas cicatriciais e de regeneração tecidual (úlceras em pele, fraturas ósseas, injúrias musculares) (Rogers et al., 1992).

Existem poucas contraindicações na utilização da acupuntura, sendo que efeitos negativos só irão ocorrer se o procedimento for feito por profissional desqualificado (Haltrecht, 1999). Animais debilitados, fracos, assustados, bravos ou agitados não devem passar por procedimentos de acupuntura. O uso em conjunto com corticosteroides é controverso na literatura (Altman, 1997). Segundo Haltrecht (1999) a acupuntura também deve ser evitada em animais gestantes.

\section{Eletroacupuntura}

A eletroacupuntura consiste na passagem de corrente elétrica através de pontos de acupuntura, e vem sido utilizada na medicina veterinária para o alcance de diminuição da sensibilidade à dor (Draehmpaehl \& Zohmann, 1997).

Os estímulos elétricos acontecem através de eletrodos aplicados nas agulhas de acupuntura já inseridas nos acupontos, usando um eletrocondutor (Altman, 1997). O uso de aparelhos com corrente alternada e onda quadrada é recomendado para evitar eletrólise e queimaduras (Altman, 1997) e possibilita o controle de frequência, que podem ser baixas (até $50 \mathrm{~Hz}$ ) e altas (de $100 \mathrm{a} 200 \mathrm{~Hz}$ ) (Luna, 2002).

$\mathrm{O}$ uso da eletroacupuntura de baixa frequência (aproximadamente $2 \mathrm{~Hz}$ ) aumenta a liberação de betaendorfina e encefalina (Joaquim et al., 2003), e fazem a estimulação de fibras motoras e nociceptivas tipo III e IV, culminando em contração muscular e parestesia (Walsh, 2001). As ondas de alta frequência $(100 \mathrm{~Hz})$ induzem à liberação de dinorfina pela medula espinhal (Han, 1993), apresentam melhores resultados no tratamento da dor (Joaquim et al., 2003) e oferecem a sensação analgésica e parestésica pela ação em conjunto das fibras aferentes tipo II, além de impedir a contração muscular, sendo usada com frequência no tratamento de afecções neuromusculares (Thomas \& Lundberg, 1994).

Joaquim et al. (2003) demonstrou sucesso no tratamento de ataxia, fraqueza, paresia e diminuição de sensibilidade usando baixas frequências da eletroacupuntura. Já para tratamento de paresia causada por discopatias toracolombares e algia cervical causadas por discopatias cervicais, o autor utilizou a eletroacupuntura de alta frequência.

Os acupontos mais utilizados para promover analgesia são Sanyinjiao (BP6) e Zusanli (E36), Hegu (IG4), Quchi (IG11) e Yanglingquan (VB34) (Taffarel \& Freitas, 2009).

Esta terapia é aplicada usando variáveis de frequência, amplitude, formatos e padrões de onda, com intervalos variados. As agulhas podem ser aplicadas nos pontos por até 20 minutos quando não estão em eletroestimulação, e quando estão sob eletroestimulação, podem variar de alguns segundos até 20 minutos (Janssens, 2001).

Um estudo feito por Joaquim et al. (2010), concluiu que o tratamento usando a eletroacupuntura foi mais efetivo que a cirurgia descompressiva tardia na recuperação do quadro neurológico de pacientes caninos com discopatias.

Em outro estudo, realizado por Freitas et al. (2011), constatou que gatas submetidas a eletroacupuntura em onda do tipo quadrada e corrente alternada, na frequência de 2 a $100 \mathrm{~Hz}$ e nos pontos Zusanli (E36) e Yanglingquan (VB34) durante ovariosalpingohisterectomia eletiva, diminuiram o consumo do anestésico inalatório (isoflurano) e tiveram estabilidade cardiorrespiratória, sendo superior uso da morfina nos parâmetros avaliados.

Em um artigo publicado por Taffarel et al. (2012), foi concluído que cadelas submetidas a eletroacupuntura nos acupontos TA5 e VB41 durante ováriohisterectomia tiveram estabilidade 
cardiorrespiratória e reduziram o volume de vapor inspirado de anestésico inalatório (isofluorano), promovendo analgesia similar ao tramadol no pós-operatório. As contraindicações são em casos de pacientes gestantes, que apresentem febre, epilepsia, em animais cardiopatas (não se deve cruzar o eixo cardíaco com os eletrodos) e em patologias agudas como o trauma.

\section{Cinesioterapia}

A cinesioterapia tem como objetivo incluir na fisioterapia exercícios terapêuticos que visam prevenir ou melhorar disfunções, restaurar ou fazer a manutenção da normalidade da força, mobilidade, flexibilidade e coordenação do animal. Esses exercícios terapêuticos vão sendo desenvolvidos conforme a evolução do quadro clínico e a resposta do animal a eles (Ramalho et al., 2015).

Todos os pacientes com algum tipo de acometimento ortopédico, que passaram pela abordagem cirúrgica ou tratamento conservativo e estão em reabilitação, em algum momento irão fazer uso da cinesioterapia. Já no pós-operatório podem ser utilizados movimentos de mobilização articular, alongamentos e exercícios de descarga de peso (Hummel \& Vicente, 2018).

A cinesioterapia pode ser aplicada a patologias musculoesqueléticas como insuficiência do ligamento cruzado cranial, luxação patelar, osteoartrose, tendinites, displasia coxofemoral e cotovelo, osteossinteses e não uniões, contraturas e distensões musculares. Assim, pode também ser indicada na prevenção de lesões em casos por exemplo de animais atletas e ainda em pacientes que se apresentam em decúbito prolongado ou com alguma restrição de movimento. A cinesioterapia também é indicada em casos de reabilitação neurológica, tanto para doenças agudas como as hérnias de disco, quanto para doenças crônicas degenerativas, como por exemplo a mielopatia degenerativa (Hummel \& Vicente, $\underline{2018})$.

Os exercícios terapêuticos aplicados na cinesioterapia, devem levar em consideração o conceito AFIRME, o qual significa alongar, fortalecer, informar, reprogramar, mobilizar e estabelecer, e isso exige do profissional habilitado intenso conhecimento de anatomia, fisiologia, fisiopatologia, biomecânica, cinesiologia, ortopedia e neurologia (Hummel \& Vicente, 2018).

Os exercícios podem ser passivos incluindo os alongamentos ou ativos como treino proprioceptivo e de ganho de força, além disso, os exercícios podem ser realizados em casa pelo próprio tutor com orientação prévia do especialista em fisioterapia, isso auxilia na aproximação do dono com animal, ajudando o tutor a perceber de forma mais rápida qualquer alteração na condição do animal (Silva et al., $\underline{2008)}$.

\section{Quiropraxia}

A quiropraxia teve iniciou nos Estados Unidos por volta 1895, através do canadense Daniel David Palmer, no grego a palavra quiropraxia significa prática com as mãos (quiro= mão; práxis = prática), e segundo seu criador esta prática pode ser definida como 'ciência, arte e filosofia de tratar com as mãos'. Esta prática é vista como uma terapia alternativa e/ou complementar aos tratamentos convencionais e tem sido amplamente reconhecida pelo mundo todo (Souza, 2006).

A Quiropraxia é uma técnica manual de manipulação da coluna vertebral e outras articulações, a qual tem como objetivo propiciar homeostase orgânica e aliviar problemas na coluna vertebral e articulações, isso ocorre através do restabelecimento do equilíbrio entre a estrutura músculo-esquelética e o sistema nervoso (Silva et al., 2008b).

Existem muitas técnicas específicas que podem ser aplicadas na quiropraxia a fim de restaurar a mobilidade de um segmento articular, porém entre as técnicas existentes, a terapia de manipulação articular (TMA), ou ajuste articular, é o procedimento mais utilizado (Bracher et al., 2013).

Esta técnica auxilia o alinhamento de articulações que estejam mal ajustadas e busca identificar causas mecânicas de doenças, como por exemplo pinçamentos e compressões nervosas, causadas por vértebras rotadas ou bloqueadas ou ainda por tensões musculares (Silva et al., 2008b).

Normalmente a manipulação articular é acompanhada por uma onda sonora, a qual é percebida como um estalo, isto acontece por causa do mecanismo de cavitação articular que ocorre durante a realização 
da manobra de manipulação. A cavitação nada mais é do que um fenômeno físico, a qual pode ter suas propriedades reproduzidas em uma articulação sinovial, isso ocorre quando a articulação é submetida a uma força de tração, fazendo com que ocorra a separação das suas superfícies articulares, gerando uma redução da pressão intra-articular do líquido sinovial, isso porque o conteúdo do espaço articular não é expansível, causando então a invaginação da cápsula articular e a redução da pressão intra-articular. A redução da pressão intra-articular abaixo da pressão de dissolução do gás carbônico leva a produção de bolhas de gás carbônico neste espaço. Por causa da formação destas bolhas, quando a manobra articular é aplicada gera uma momentânea interrupção da força de coaptação entre as superfícies articulares, levando a uma rápida separação entre elas, e esta rápida separação faz com ocorra uma tensão na cápsula articular, fazendo com que os tecidos periarticulares vibrem gerando então a emissão da onda sonora (Bracher et al., 2013).

O ajuste quiroprático feito de forma adequada e precisa nas articulações que de fato manifestam alterações biomecânicas, auxilia de forma eficaz na restauração da mobilidade, na redução da dor e na restituição da função articular dentro dos padrões fisiológicos. Ainda outros métodos manuais como mobilização articular, orientação de exercícios e técnicas de relaxamento muscular também podem ser associadas ao tratamento dos pacientes (Bracher et al., 2013).

Para realização inicial da quiropraxia é importante fazer uma anamnese completa, com objetivo de entender melhor a condição atual do paciente e demais detalhes que possam ter relevância para a instituição de um protocolo de tratamento, depois disso se faz então o exame físico, que permite ao especialista ter uma ideia mais clara da condição clínica que o paciente apresenta e a partir disso decidir a instituição do melhor protocolo de tratamento para cada paciente (Bracher et al., 2013).

Desta forma, a quiropraxia pode ser indicada para o tratamento de diferentes patologias que acometem cães e gatos, dentre elas podemos citar como exemplo a artrite, artrose, displasia coxofemoral e outros múltiplos problemas degenerativos associados ao sistema locomotor, podendo também ser indicada nos casos de hérnias de disco agudas ou crônicas, problemas gastro-intestinais e ainda casos de comprometimento de mobilidade e flexibilidade causados por algum tipo de traumatismo físico que tenha acometido o animal (Silva et al., 2008b).

\section{Eletroterapia}

Eletroterapia é o nome dado ao tratamento realizado por meio da aplicação de uma corrente elétrica, gerada por um fluxo de átomos livres através da matéria quando os corpos possuem uma diferença de potencial elétrico. A diferença de potencial origina então uma tensão elétrica que consegue produzir o movimento das cargas elétricas transferindo energia de um corpo para outro (Baptistella, 2013).

A corrente elétrica é aplicada na pele do animal através de eletrodos, gerando uma eletroestimulação dos músculos inervados pelos nervos motores periféricos, fazendo com que haja a despolarização desses nervos, resultando então na contração do músculo (Cruz \& Santos, 2017). Essa eletroestimulação dos músculos por meio dos nervos periféricos a fim de gerar uma contração muscular, é denominada de Estimulação elétrica neuromuscular (Silva et al., 2013).

Isso é possível porque os nervos e músculos são tecidos excitáveis, e por isso apresentam permeabilidade da membrana celular sensível à voltagem, sendo assim, quando ocorre a estimulação elétrica, a membrana do neurônio atinge o seu limiar de despolarização e produz um impulso nervoso, o qual se propagará até alcançar a placa motora, permitindo que ocorra então a contração muscular (Baptistella, 2013).

A estimulação elétrica neuromuscular através do sistema nervoso periférico, tem por objetivo produzir contração muscular com a finalidade de restaurar, manter ou melhorar a capacidade funcional dos músculos, e pode ser utilizada no tratamento de disfunções neuromusculares, desuso de membros, atrofia muscular de qualquer origem, e ainda fraqueza ou queda da resistência física, por exemplo (Baptistella, 2013; Silva et al., 2013).

A eletroterapia possui dentro dela duas técnicas diferentes, as quais abrangem finalidades distintas no tratamento do paciente, uma delas é a eletroanalgesia (TENS) e a outra é a eletroestimulação (NMES). A eletroanalgesia é aplicada através da estimulação elétrica nervosa transcutânea (TENS) e 
tem como objetivo promover alívio na percepção da dor, já a Neuromuscular Electrical Stimulation (NMES) é indicada para casos que exigem reeducação muscular, redução dos espasmos, retardo da atrofia e trabalho de fortalecimento muscular, ainda na técnica de NMES existe a função chamada Functional Electrical Stimulations (FES), a qual compreende a contração muscular para ajudar a aumentar o tônus muscular e ainda prevenir atrofias (Cruz \& Santos, 2017).

A técnica de analgesia do TENS funciona por meio de um mecanismo fundamentado na teoria das comportas, assim a eletroestimulação gerada nos receptores cutâneos caminham através das fibras largas aferentes e atingem primeiro o portão no corno dorsal da medula fazendo o seu bloqueio e desta forma leva a inibição dos impulsos de dor que chegam através das fibras de menor calibre (Cruz \& Santos, 2017). O TENS é indicado principalmente para casos que precisam de alívio da dor, uma vez que ele é eficaz em promover analgesia, e ainda pode ser utilizado diariamente (Ramalho et al., 2015).

A técnica de Functional Electrical Stimulations (FES), a qual produz a contração muscular, atua causando a despolarização do nervo motor, gerando assim uma resposta sincrônica em todas as unidades motoras do músculo trabalhado, resultando em uma eficiente contração do mesmo, porém em casos que o membro encontra-se paralisado por exemplo, não é possível obter um movimento funcional somente por meio de um simples pulso elétrico, nesses casos é necessário que ocorra uma sequência de estímulos, com duração, frequência de repetição e intensidade adequadas. A intensidade precisa ser ajustada de acordo com a resposta apresentada pelo paciente para que não ocorra o fenômeno da acomodação, ou seja, quando após algum tempo de aplicação da corrente elétrica com o mesmo estímulo, ela passa a não ser mais eficiente para despolarizar essas fibras, sendo necessário então elevar a intensidade do estimulo para que isso volte a acontecer (Baptistella, 2013).

A eletroestimulação é aplicada na pele do animal por meio de eletrodos, esses eletrodos serão os responsáveis pela passagem da corrente elétrica, eles podem ser feitos de diversos materiais como silicone, autoadesivos ou metal, porém na fisioterapia veterinária os mais utilizados são os de silicone. O tamanho dos eletrodos varia de acordo com o tamanho da área que se quer atingir, e o posicionamento dos eletrodos na pele do animal vai depender do tipo de corrente elétrica e da finalidade do tratamento. Quando se utiliza a eletroterapia é preciso ter alguns cuidados para colocação dos eletrodos, como fazer tricotomia da área a ser tratada e aplicar bastante gel na pele do animal a fim de reduzir o espaço entre os pelos, o gel ajuda a retirar o ar encontrado nesses espaços e desta forma otimiza a passagem da corrente elétrica (Baptistella, 2013; Kistemacher, 2017).

A utilização da eletroterapia é recomendada principalmente para analgesia, fortalecimento muscular, redução de edemas, relaxamento de espasmos musculares, acelerar cicatrização de fraturas, melhorar a mobilidade articular, aumentar a circulação e pode ainda agir como bactericida. Já as contraindicações para seu uso são por exemplo, região de útero gravídico, pacientes que possuem marca-passo, pacientes com lesões de pele, regiões que apresentem tumores, regiões onde há exposição da medula espinhal, pacientes epiléticos, seios carotídeos, gânglios cervicais, olhos, ouvidos, coração, áreas com sensação diminuída e sobre áreas com trombose ou tromboflebite (Baptistella, 2013; Kistemacher, 2017; Silva et al., 2013).

\section{Referências bibliográficas}

Agne, J. E. (2016). Eletrotermofototerapia. In Eletrotermofototerapia (3. ed, San, p. 448).

Al-Watban, F. A. H., \& Andres, B. L. (2000). Laser photons and pharmacological treatments in wound healing. Laser therapy, 12(1), 3-11. https://doi.org/10.5978/islsm.12.3

Altman, S. (1992). Terapia pela acupuntura na clínica de pequenos animais. ETTINGER, SJ Tratado de Medicina Interna Veterinária: Moléstias Do Cão e Do Gato. 3ed. São Paulo: Manole, 1, 454-459.

Altman, Sheldon. (1997). Acupuncture therapy in small animal practice. The Compendium on Continuing Education for the Practicing Veterinarian (USA), 19, 1238-1244.

Alves, M. V. L. D., Sturion, M. A. T., \& Córdova Gobetti, S. T. (2019). Aspectos gerais da fisioterapia e reabilitação na medicina veterinária. Ciência Veterinária UniFil, 1(3), 69-78.

Andrade, F. S. S. D., Clark, R. M. O., \& Ferreira, M. L. (2014). Effects of low-level laser therapy on wound healing. Revista Do Colégio Brasileiro de Cirurgiões, 41(2), 129-133. 
https://doi.org/10.1590/S0100-69912014000200010

Baptistella, J. C. (2013). Hidroterapia e eletroterapia em ratos com denervação do nervo isquiático. Dissertação (Mestrado em Ciência Animal Fisiopatologia Médica e Cirúrgica de pequenos animais). Faculdade de Medicina Veterinária - UNESP, Campus de Araçatuba, São Paulo, 2013.

Baxter, G. D., \& McDonough, S. M. (2007). Principles of electrotherapy in veterinary physiotherapy. Animal Physiotherapy: Assessment, Treatment and Rehabilitation of Animals. Oxford: Blackwell, 177-186.

Bjordal, J. M., Lopes-Martins, R. A., Joensen, J., Couppe, C., Ljunggren, A. E., Stergioulas, A., \& Johnson, M. I. (2008). A systematic review with procedural assessments and meta-analysis of Low Level Laser Therapy in lateral elbow tendinopathy (tennis elbow). BMC Musculoskeletal Disorders, 9(1), 75. https://doi.org/10.1186/1471-2474-9-75

Bocci, V. (2005). Ozone. A New Medical Drug. Springer Netherlands. https://doi.org/10.1007/1-4020$\underline{3140-8}$

Bocci, V., Zanardi, I., \& Travagli, V. (2011). Oxygen/ozone as a medical gas mixture. A critical evaluation of the various methods clarifies positive and negative aspects. Medical Gas Research, 1(1), 6. https://doi.org/10.1186/2045-9912-1-6

Bockstahler, B., L, M. D., Levine, D., \& Mueller, M. (2004). Métodos de Fisioterapia. In Métodos de Fisioterapia. In: Fisioterapia en perros y gatos rehabilitación y manejo del dolor. Editores $B$ Bockstahler, D Levine, D Millis. Veterinaria Esteve, Barcelona (pp. 46-123).

Borges, T. L., Marangoni, Y. G., Joaquim, J. G. F., Rosseto, V. J. V., \& Nitta, T. Y. (2019). Ozonioterapia no tratamento de cães com dermatite bacteriana: relato de dois casos. Revista Científica de Medicina Veterinária, XVI, 32, Periódico Semestral.

Bracher, E. S. B., Benedicto, C. C., \& Facchinato, A. P. A. (2013). Quiropraxia. Revista de Medicina, 92(3), 173. https://doi.org/10.11606/issn.1679-9836.v92i3p173-182

Carr, B. J., \& Canapp, D. (2014). Sports medicine assessment of the agility dog. Clean Run, 12, 49-52.

Carrie, M. H., \& Brody, L. T. (2005). Therapeutic exercise, Moving toward Function. A Wolters Kluwer Company Lippincott Williams \& Wilkim, 31, 255-263.

Cassu, R. N. (2002). Avaliação dos efeitos cardiorrespiratório, endócrino e analgésico da eletroacupuntura em cães. Tese Doutorado Em Anestesiologia. Faculdade de Medicina, Universidade Estadual de São Paulo, Botucatu. 196p.

Channual, J., Choi, B., Osann, K., Pattanachinda, D., Lotfi, J., \& Kelly, K. M. (2008). Vascular effects of photodynamic and pulsed dye laser therapy protocols. Lasers in Surgery and Medicine, 40(9), 644-650. https://doi.org/10.1002/lsm.20673

Chen, A. C.-H., Huang, Y.-Y., Sharma, S. K., \& Hamblin, M. R. (2011). Effects of 810-nm Laser on Murine Bone-Marrow-Derived Dendritic Cells. Photomedicine and Laser Surgery, 29(6), 383-389. https://doi.org/10.1089/pho.2010.2837

Cruz, D. C. F. D., \& Santos, M. M. (2017). Tratamento Fisioterápico em Cão com Discopatia Toracolombar. Anais do ICESP Promove., 2271-2276.

Dawidson, I., Angmar-Månsson, B., Blom, M., Theodorsson, E., \& Lundeberg, T. (1999). Sensory stimulation (acupuncture) increases the release of calcitonin gene-related peptide in the saliva of xerostomia sufferers. Neuropeptides, 33(3), 244-250. https://doi.org/10.1054/npep.1999.0759

Demir, H., Menku, P., Kirnap, M., Calis, M., \& Ikizceli, I. (2004). Comparison of the effects of laser, ultrasound, and combined laser + ultrasound treatments in experimental tendon healing. Lasers in Surgery and Medicine, 35(1), 84-89. https://doi.org/10.1002/1sm.20046

Di Maio, L. V., Urruchi, W., \& Rodríguez, Z. Z. (2009). Utilidad potencial de la ozonoterapia en la Medicina Veterinaria. REDVET. Revista Electrónica de Veterinaria, 10(10), 1-13.

Draehmpaehl, D., \& Zohmann, A. (1997). Acupuntura no cão e no gato: princípios básicos e prática cientifica. Roca.

Ferreira, L. (2010). Fisioterapia e reabilitação física em animais de companhia. Trabalho Final de Curso de Enfermagem Veterinária. Instituto Politécnico de Viseu, 102. 
Freitas, P. M. C., Pignaton, W., Simões, J. R., Zacché, E., Luz, M. R., Salgado, A. E. P., Taffarel, M. O., Eurides, D., \& Baungarten, L. B. (2011). Eletroacupuntura e morfina sobre parâmetros cardiorrespiratórios em gatas submetidas à ovariosalpingohisterectomia eletiva. Revista Brasileira de Saúde e Produção Animal, 12(4).

Frigo, L., Luppi, J. S., Favero, G. M., Maria, D. A., Penna, S. C., Bjordal, J. M., Bensadoun, R. J., \& Lopes-Martins, R. A. (2009). The effect of low-level laser irradiation (In-Ga-Al-AsP - $660 \mathrm{~nm}$ ) on melanoma in vitro and in vivo. BMC Cancer, 9(1), 404. https://doi.org/10.1186/1471-2407-9-404

Garcia, C. A., Stanziola, L., Andrade, I. C. V, Naves, J. H. F., Neves, S. M. N., \& Garia, L. A. D. (2008). Autohemoterapia maior ozonizada no tratamento de erliquiose canina-relato de caso. Congresso Brasileiro de Medicina Veterinária, 35.

Gonçalves, J. O. S., Paiva, P. O. P., \& Oliveira, L. B. G. (2020). Uso da ozonioterapia como auxiliar no tratamento de cão portador de leishmaniose: relato de caso. Pubvet, 14(1), 1-4. https://doi.org/10.31533/pubvet.v14n1a495.1-4

Gross, D. (2014). Introduction to Therapeutic Lasers in a Rehabilitation Setting. Topics in Companion Animal Medicine, 29(2), 49-53. https://doi.org/10.1053/j.tcam.2014.09.004

Gurley, B. (1985). Ozone: pharmaceutical sterilant of the future? PDA Journal of Pharmaceutical Science and Technology, 39(6), 256-261.

Haddad, M. A., Souza, M. V, Hincapie, J. J., Ribeiro Junior, J. I., Ribeiro Filho, J. D., \& Benjamin, L. A. (2009). Comportamento de componentes bioquímicos do sangue em equinos submetidos à ozonioterapia. Arquivo Brasileiro de Medicina Veterinaria E Zootecnia, 61(3), 539-546. https://doi.org/http://dx.doi.org/10.1590/S0102-09352009000300003.

Haltrecht, H. (1999). Veterinary acupuncture. The Canadian Veterinary Journal = La Revue Veterinaire Canadienne, 40(6), 401-403. http://www.ncbi.nlm.nih.gov/pubmed/10367155

Han, J.-S. (1993). Acupuncture and Stimulation Produced Analgesia. In Herz A., Akil H., Simon EJ (eds) Opioids II. Handbook of Experimental Pharmacology, vol 104 / 2. Springer, Berlin, Heidelberg. (pp. 105-125). https://doi.org/10.1007/978-3-642-77540-6_5

Hernández, O. D., \& González, R. C. (2001). Ozonoterapia en úlceras flebostáticas. Revista Cubana de Cirugía, 40(2), 123-129.

Hummel, J., \& Vicente, G. (2018). Tratado de Fisioterapia e Fisiatria de Pequenos Animais - $1^{a}$ Edição Payá, São Paulo, SP.

Jackson, A. M., Millis, D. L., Stevens, M., \& Barnett, S. (2002). Joint kinematics during underwater treadmill activity. Second International Symposium: On Rehabilitation and Physical Therapy in Veterinary Medicine, 191.

Janssens, L. A. A. (2001). Acupuncture for thoracolumbar and cervical disk disease. Veterinary Acupuncture, 193-198.

Joaquim, J G F, Luna, S. P. L., Torelli, S., Angeli, A. L., \& Gama, E. D. (2003). Study of 43 dogs with neurological disease: a western and eastern view of the neurological pattern of diseases. 29th Annиal International Congress On Veterinary Acupuncture, 289-297.

Joaquim, Jean G. F., Luna, S. P. L., Brondani, J. T., Torelli, S. R., Rahal, S. C., \& Freitas, F. P. (2010). Comparison of decompressive surgery, electroacupuncture, and decompressive surgery followed by electroacupuncture for the treatment of dogs with intervertebral disk disease with long-standing severe neurologic deficits. Journal of the American Veterinary Medical Association, 236(11), 12251229. https://doi.org/10.2460/javma.236.11.1225

Kistemacher, B. G. (2017). Tratamento fisioterápico na reabilitação de cães com afecções em coluna vertebral: revisão de literatura. Graduação Em Medicina Veterinária. Universidade Federal Do Rio Grande do Sul, Porto Alegre., 50.

Kitchen, S. S., \& Partridge, C. J. (1991). A Review of Low Level Laser Therapy: Part I: Background, Physiological Effects and Hazards. Physiotherapy, 77(3), 161-168. https://doi.org/10.1016/S00319406(10)61694-X

Konlian, C. (1999). Aquatic therapy: making a wave in the treatment of low back injuries. Orthopaedic Nursing, 18(1), 11. 
Lake, J. C., Felberg, S., Malavazzi, G. R., Goulart, D. A., Nishiwaki-Dantas, M. C., \& Dantas, P. E. C. (2004). Efeito terapêutico da aplicação intra-ocular de ozônio em modelo experimental de endoftalmite por Staphylococcus epidermidis em coelhos. Arquivos Brasileiros de Oftalmologia, 67(4), 575-579. https://doi.org/10.1590/S0004-27492004000400003

Lam, K. K. K. (2008). Ozone Disinfection of SARS-Contaiminated Areas. Contaiminated Areas. Hong Kong, 2860, 1-6.

Langevin, H. M., Churchill, D. L., \& Cipolla, M. J. (2001). Mechanical signaling through connective tissue: a mechanism for the therapeutic effect of acupuncture. The FASEB Journal, 15(12), 22752282. https://doi.org/10.1096/fj.01-0015hyp

Leite, R. C. (1999). Ozonio. 1. Ed. Curitiba: Corpo Mente Publicações, 138.

Levine, D., Millis, D. L., Marcellin-Little, D. J., \& Taylor, R. (2008). Reabilitação e fisioterapia na prática de pequenos animais. Roca.

Liu, X.-G., Zhou, Y.-J., Liu, T. C.-Y., \& Yuan, J.-Q. (2009). Effects of Low-Level Laser Irradiation on Rat Skeletal Muscle Injury after Eccentric Exercise. Photomedicine and Laser Surgery, 27(6), 863869. https://doi.org/10.1089/pho.2008.2443

Low, J., Ward, A., Robertson, V., \& Reed, ANN. (2001). Eletroterapia explicada: princípios e prática. Elsevier Brasil.

Luna, S. P. L. (2002). Emprego da acupuntura em anestesia. FANTONI, DT; CORTOPASSI, SRG Anestesia Em Cães e Gatos. São Paulo: Roca, 337-343.

Marsolais, G. S., McLean, S., Derrick, T., \& Conzemius, M. G. (2003). Kinematic analysis of the hind limb during swimming and walking in healthy dogs and dogs with surgically corrected cranial cruciate ligament rupture. Journal of the American Veterinary Medical Association, 222(6), 739743. https://doi.org/10.2460/javma.2003.222.739

Martín, F. M. (2014). Manual de fisioterapia en pequeños animales. Barcelona: Multimédica Ediciones Veterinarias. Págs, 447, 543.

Mattos, L. H. L. (2012). Efeito da fototerapia com doidos superluminosos (890nm) na reparação tendínea: modelo experimental em ovinos.-. Dissertação (Mestrado) - Universidade Estadual Paulista Júlio de Mesquita Filho, Faculdade de Medicina Veterinária e Zootecnia, 2012., 92. http://hdl.handle.net/11449/88917

McGowan, C., \& Goff, L. (2016). Animal physiotherapy: assessment, treatment and rehabilitation of animals (p. 376). John Wiley \& Sons.

Mikail, S., \& Pedro, C. R. (2009). Fisioterapia veterinária (p. 264). São Paulo: Editora Manole.

Moda, T. F., Lima, C. J., Fernandes, A. B., Zângaro, R. A., \& Moreira, L. H. (2014). Efeitos da ozonização intra-abdominal e intra-retal sobre uma avaliação renal de cães acometidos por Leishmaniose Visceral. XXIV Congresso Brasileiro de Engenharia Biomédica-CBEB Uberlândia, Minas Gerais, Brasil.

Monk, M. L., Preston, C. A., \& McGowan, C. M. (2006). Effects of early intensive postoperative physiotherapy on limb function after tibial plateau leveling osteotomy in dogs with deficiency of the cranial cruciate ligament. American Journal of Veterinary Research, 67(3), 529-536. https://doi.org/10.2460/ajvr.67.3.529

Moshkovska, T. (2005). It is time to test low level laser therapy in Great Britain. Postgraduate Medical Journal, 81(957), 436-441. https://doi.org/10.1136/pgmj.2004.027755

Nakao, A., Sugimoto, R., Billiar, T. R., \& McCurry, K. R. (2009). Therapeutic Antioxidant Medical Gas. Journal of Clinical Biochemistry and Nutrition, 44(1), 1-13. https://doi.org/10.3164/jcbn.08$\underline{193 R}$

Nogales, C. G., Ferrari, P. H., Kantorovich, E. O., \& Lage-Marques, J. L. (2008). Ozone therapy in medicine and dentistry. The Journal of Contemporary Dental Practice, 9(4), 75-84.

Noris, M. (2003). The biological mechanisms of acupuncture. 29th International Congress on Veterinary Acupuncture Proceedings. Brasil: Ed. Santos SP, 83-92.

Oliveira, H. H., Lima, C. J., Fernandes, A. B., Zangaro, R. A., \& Moreira, L. H. (2014). Uso de óleo 
ozonizado no tratamento tópico de infestação por carrapato em cão-Relato de caso. Brazilian Journal of Veterinary Medicine, 36(4), 405-408.

Oliveira, J. T. C. (2007). Revisão sistemática de literatura sobre o uso terapêutico do ozônio em feridas [Universidade de São Paulo]. https://doi.org/10.11606/D.7.2007.tde-20122007-094050

Pinheiro, A., Almeida, P., \& Soares, L. G. (2017). Princípios fundamentais dos lasers e suas aplicações. Biotecnologia Aplicada à Agro\&indústria, 815-888.

Pino, E. R. del, Serrano, M. A., Río, M. R. del, \& Garrido, M. de los A. (1999). Aspectos de la ozonoterapia en pacientes con neuropatía periférica epidémica. Revista Cubana de Enfermería, 15(2), 114-118.

Plaja, J. (2003). Analgesia por medios físicos. McGraw-Hill/Interamericana.

Ramalho, F. P., Formenton, M. R., Isola, J. G. M. P., \& Joaquim, J. F. G. (2015). Tratamento de doença de disco intervertebral em cão com fisioterapia e reabilitação veterinária: relato de caso. Revista de Educação Continuada em Medicina Veterinária e Zootecnia do CRMV-SP, 13(1), 10-17. https://doi.org/10.36440/recmvz.v13i1.25561

Riegel, R. J., \& Godbold, J. C. (2017). Laser Therapy in Veterinary Medicine: Photobiomodulation. John Wiley \& Sons.

Rifá, E. D., \& Musa, J. V. Q. (2005). Ozonoterapia intraarticular en la enfermedad artrósica de rodilla. Revista Cubana de Ortopedia y Traumatología, 19(1).

Robertson, V., Ward, A., Low, J., \& Reed, A. (2009). Eletroterapia Explicada. Princípios e Prática. $4^{o}$ Edição. Editora Elsevier.

Rogers, P. A., Schoen, A. M., \& Limehouse, J. (1992). Acupuncture for immune-mediated disorders. Literature review and clinical applications. Problems in Veterinary Medicine, 4(1), 162-193. http://www.ncbi.nlm.nih.gov/pubmed/1581655

Scognamillo-Szabó, M. V. R., \& Bechara, G. H. (2001). Acupuntura: bases científicas e aplicações. Ciência Rural, 31(6), 1091-1099.

Silva, D. T., Alves, G. C., \& Filadelpho, A. L. (2008a). Fisioterapia aplicada à Medicina VeterináriaRevisão. Revista Científica Eletrônica de Medicina Veterinária, Ano, 6.

Silva, D. T., Alves, G. C., \& Filadelpho, A. L. (2008b). Medicina alternativa: Acupuntura e quiropraxia aplicadas em medicina veterinária-Revisão. Revisão. Revista Científica Eletrônica de Medicina Veterinária, Garça-SP, 6, 11 .

Silva, L. V., Barioni, G., \& Silva, A. V. P. (2013). Uso da estimulação elétrica neuromuscular em cães. PUBVET, 7, 1653-1790.

Silva, T. C., Shiosi, R. K., \& Raineri Neto, R. (2018). Ozonioterapia: um tratamento clínico em ascensão na medicina veterinária-revisão de literatura. Revista Científica de Medicina Veterinária.

Silva, V. E. G., Correa, I. H., \& Santos, J. M. G. (2014). Aplicação da ozonioterapia na medicina veterinária. VII Mostra Interna de Trabalhos de Iniciação Científica- UNICESUMAR PESQUISAS/ Maringá-PR, ISBN 978-85-8084-724-6, 4.

Souza, F. B. (2009). Auto-hemoterapia como terapia auxiliar no tratamento de tumor venéreo transmissível. Monografia Apresentada a Faculdade Ucb Para Título de Especialista; Goiânia.

Souza, M. M. (2006). Manual de Quiropraxia, Quiroprática, Quiropatia: filosofia, ciência, arte e profissão de curar com as mãos. São Paulo: Ibraqui Livros.

Sterin, G. M. (2001). Terapia Física y Rehabilitación en Medicina Veterinaria; Introducción.

Taffarel, M.O., Salgado, A. E. P., Melo Filho, E. V., Teixeira, L. R., Fracalossi, L. D. C., Luz, M. R., \& Freitas, P. M. C. (2012). Efeitos da eletroacupuntura, aquapuntura e farmacopuntura em cadelas anestesiadas com isofluorano e submetidas à ovário-histerectomia. Arquivo Brasileiro de Medicina Veterinária e Zootecnia, 64(1), 23-31. https://doi.org/10.1590/S0102-09352012000100004

Taffarel, Marilda Onghero, \& Freitas, P. M. C. (2009). Acupuntura e analgesia: aplicações clínicas e principais acupontos. Ciência Rural, 39(9), 2665-2672. https://doi.org/10.1590/S0103$\underline{84782009000900047}$

Thomas, M., \& Lundberg, T. (1994). Importance of modes of acupuncture in the treatment of chronic 
nociceptive low back pain. Acta Anaesthesiologica Scandinavica, 38(1), 63-69. https://doi.org/10.1111/j.1399-6576.1994.tb03839.x

Velano, H. E., Nascimento, L. C., Barros, L. M., \& Panzeri, H. (2001). Avaliação in vitro da atividade antibacteriana da água ozonizada frente ao Staphylococcus aureus. Pesquisa Odontológica Brasileira, 15(1), 18-22. https://doi.org/10.1590/S1517-74912001000100004

Venezian, G. C., Silva, M. A. M. R., Mazzetto, R. G., \& Oliveira Mazzetto, M. (2010). Low Level Laser Effects On Pain to Palpation and Electromyographic Activity in TMD Patients: A Double-Blind, Randomized, $\quad$ Placebo-Controlled $\quad$ Study. $\quad C R A N I O^{\circledR}, \quad 28(2), \quad 84-91$. https://doi.org/10.1179/crn.2010.012

Viebahn-Haensler, R. (2001). Milestones of Medical Ozone: Medical Ozone as a Focal Point of Criticism. Medical Society for Ozone Application in Prevention and Therapy Nordring 8, D-76473 Iffezheim, Germany, 12, 8.

Viebahn, R. (1994). The Use of Ozone in Medicine: A Practical Handbook (M. B. R. E. (1 dezembro 1994) (ed.)).

Vilarindo, M. C., Andreazzi, M. A., \& Fernandes, V. S. (2013). Considerações Sobre o Uso da Ozonioterapia na Clínica Veterinária. VIII EPCC-Encontro Internacional de Produção Científica Cesumar-Centro Universitário Cesumar Editora CESUMAR Maringá, Paraná, Brasil.

Waining, M., Young, I. S., \& Williams, S. B. (2011). Evaluation of the status of canine hydrotherapy in the UK. Veterinary Record, 168(15), 407-407.https://doi.org/10.1136/vr.c6842

Walsh, D. (2001). Acupuntura e técnicas relacionadas à fisioterapia. In Hopwood, V., Lovesey, M., Mokone, S. Acupuntura e técnicas relacionadas à fisioterapia. Barueri: Manole, cap.09, p.119-27.

Yamamura, Y. (2002). Efeitos da acupuntura, evidenciados por estudos clínicos e experimentais controlados, realizados na Universidade Federal de São Paulo/Escola Paulista de Medicina, no período de 1992 a 2002. Tese (Livre Docência Em Ortopedia e Traumatologia), Faculdade de Medicina Da Universidade Federal de São Paulo, São Paulo., 81.

Recebido: 26 de junho, 2020.

Aprovado: 31 de julho, 2020.

Disponível online: 3 de outubro, 2020.
Licenciamento: Este artigo é publicado na modalidade Acesso Aberto sob a licença Creative Commons Atribuição 4.0 (CC-BY 4.0), a qual permite uso irrestrito, distribuição, reprodução em qualquer meio, desde que o autor e a fonte sejam devidamente creditados 